Research Article

\title{
Modeling and Analysis of Variable Speed Wind Turbine equipped with PMSG
}

\author{
Sanjiba Kumar Bisoyi ${ }^{\dot{A}^{*}}$, R.K.Jarial ${ }^{\dot{\mathrm{A}}}$ and R.A.Gupta ${ }^{\dot{\mathrm{B}}}$

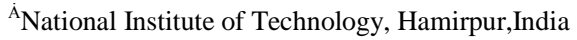 \\ ${ }^{\dot{B}}$ Malviya National Institute of Technology,Jaipur,Rajasthan,India
}

Accepted 10 January 2014, Available online 01 February 2014, Special Issue-2, (February 2014)

\begin{abstract}
This paper presents the dynamic model and Detail Analysis of a Wind energy conversion system equipped with permanent magnet synchronous generator (PMSG). There are different types of synchronous generators, but the PMSG is chosen, in order to obtain its dynamic model. It offers better performance due to higher efficiency and less maintenance since it does not have rotor current and can be used without a gearbox, which also implies a reduction of the weight of the nacelle and a reduction of costs. Along with the PMSG, wind speed, wind turbine \&drive train have been modelled and the mathematical equations that explain their behaviour have been introduced. The generator model is established in the dq-synchronous rotating reference frame. The wind turbine model details the mechanism of variable speed operation of the turbine. In order to verify the presented model simulations with MATLAB/Simulink software have been conducted. Simulation results prove the validity of the model. Moreover, the concept of the Maximum Power Point Tracking (MPPT) has been presented in terms of the adjustment of the generator rotor speed according to instantaneous wind speed.
\end{abstract}

Keywords: Modelling, MPPT, Wind Speed, Drive train, Wind Turbine, PMSG

\section{Introduction}

Wind energy is one of the best technologies available today to provide a sustainable supply to the world development, due to abundant, inexhaustible potential, increasingly competitive cost, and environmental advantage. By the end of 2003.According to Global wind energy council the total installed capacity of the wind turbines has reached as much as $39.234 \mathrm{GW}$ and will exceed $110 \mathrm{GW}$ by the year of 2012. In depth understanding and investigation of wind energy related technologies, such as wind power generators, wind farm integration, grid code and etc., is very meaningful. In terms of the generators for wind-power application, there are different concepts in use today. The major distinction among them is made between fixed speed and variable speed wind turbine generator concepts. In the early stage of wind power development, fixed-speed wind turbines and induction generators were often used in wind farms. But the limitations of such generators, e.g. low efficiency and poor power quality, adversely influence their further application. With large-scale exploration and integration of wind sources, variable speed wind turbine generators, such as doubly fed induction generators (DFIGs) and permanent magnet synchronous generators (PMSGs) are emerging as the preferred technology (M. Chinchilla et al 2006). In contrast to their fixed-speed counterparts, the variable speed generators allow operating wind turbines at

*Corresponding author: Sanjiba Kumar Bisoyi

DOI: http://dx.doi.org/10.14741/ijcet/spl.2.2014.78 the optimum tip-speed ratio and hence at the optimum power efficient for a wide wind speed range. However, the variable-speed directly-driven multi-pole permanent magnet synchronous generator (PMSG) wind architecture is chosen for this purpose and it is going to be modelled: it offers better performance due to higher efficiency and less maintenance because it does not have rotor current. What is more, PMSG can be used without a gearbox, which implies a reduction of the weight of the nacelle and reduction of costs. Optimum wind energy extraction is achieved by running the Wind Turbine Generator (WTG) invariable speed because of the higher energy gain and the reduced stresses. Using the Permanent Magnet Synchronous Generator (PMSG) the design can be even more simplified. However, the recent advancements in power electronics and control strategies have made it possible to regulate the voltage of the PMSG in many different ways. The present research analyses the model of a variable speed wind turbine equipped with $2 \mathrm{MW}$ PMSG. It must be noted that the present research focuses neither on the converter (grid side and rotor side) nor on their controls.

\section{Wind Energy Conversion}

The circuit diagram for WECs system connected to three phase grid at the point of common coupling (PCC) is shown in the Fig. 1. The main components of the system are wind turbine, PMSG, dual-stage converter comprising of AC-DC rectifier and voltage source inverter (VSI), 
local load and the grid. The wind turbine is connected to PMSG through drive train \& connected to back to back converter. The AC-DC converter is connected to VSI via DC link capacitor $(C)$. The voltage across $C$ is maintained constant, through the outer voltage controller loop of VSI, to facilitate complete active power transfer to the AC side of the VSI. The VSI is controlled using sinusoidal pulse width modulation strategy to feed active $(\mathrm{P})$ and reactive power $(\mathrm{Q})$ to the local load and the utility. The system is loaded with both static and dynamic load. The grid with voltage Vgrid is connected at the PCC and is assumed to be capable of absorbing active and reactive power, whenever the power generated from the wecs system is more in comparison to the load power demand and viceversa.

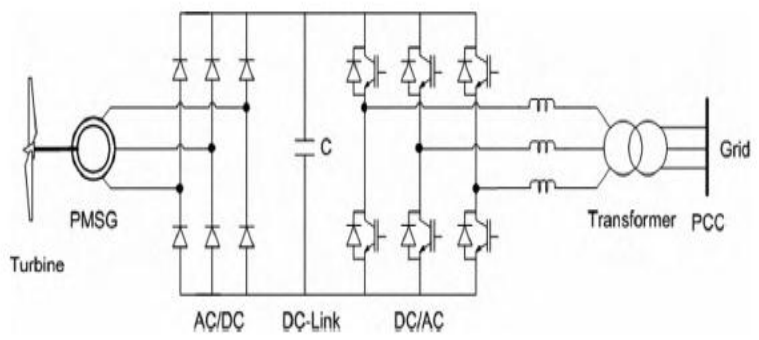

Fig.1 Typical grid connected WECS

\subsection{Wind speed modeling}

The wind speed model consists of a source that generates a wind speed signal to be applied to the wind turbine. The wind speed signal consists of four components, namely the mean wind speed; a wind speed ramp, which is a steady increase in the mean wind speed; a wind gust; and turbulence. The eventual wind speed to be applied to the wind turbine is the sum of these four components as presented by (P. M. Anderson et al 1983)

$$
V_{w}(t)=V_{b}(t)+V_{r}(t)+V_{g}(t)+V_{n}(t)
$$

Where $V_{b}$ is the base (constant) wind component, $V_{r}$ is the ramp wind component, $\mathrm{V}_{\mathrm{g}}$ is the gust wind component and $V_{n}$ is the base noise wind component, all of them in $\mathrm{m} / \mathrm{s}$. Fig. 2.Shows the graphics of the non-constant wind speed components: ramp, gust and noise components. The present work considers a constant wind speed equal to 12 $\mathrm{m} / \mathrm{s}$. with ramp, gust and random noise component, consequently, the model implementation of the wind speed in Simulink implies the consideration of the base wind speed component, as shown in Fig. 3.
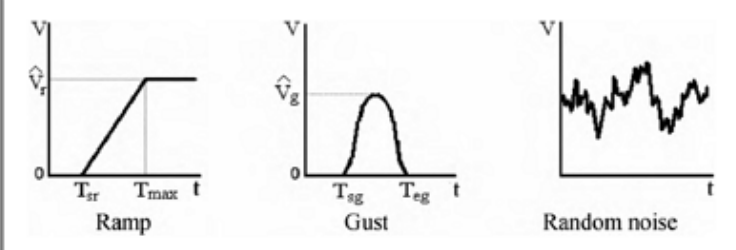

Fig.2 Non constant wind speed components

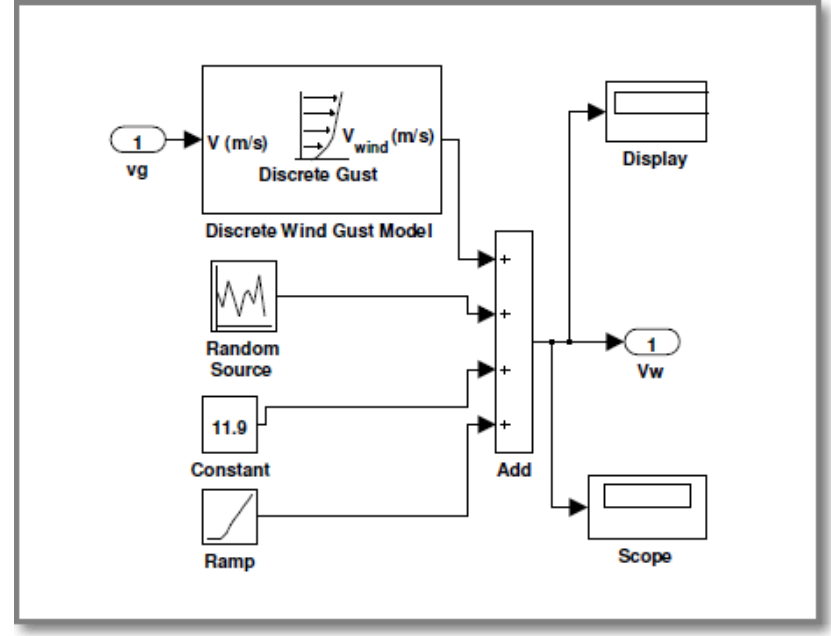

Fig.3 Wind speed model with Simulink

\subsection{Wind turbine modeling}

Wind turbines cannot fully capture wind energy. The components of wind turbine have been modeled by the following equations. Output aerodynamic power of the wind-turbine is expressed as

$$
P_{\text {Turbine }}=\frac{1}{2} C_{p}(\lambda, \beta) \rho \mathrm{A} V^{3}
$$

Where, $\rho$ is the air density (typically $1.225 \mathrm{~kg} / \mathrm{m} 3$ ), $A$ is the area swept by the rotor blades (in $\mathrm{m}^{2}$ ) $C p$ is the coefficient of power conversion and $V$ is the wind speed (in $\mathrm{m} / \mathrm{s}$ ).The tip-speed ratio is defined as

$\lambda=\frac{W_{m R}}{V}$

Where $\mathrm{Wm}$ and $R$ are the rotor angular velocity (in $\mathrm{rad} / \mathrm{sec}$ ) and rotor radius (in $\mathrm{m}$ ), respectively. The wind turbine mechanical torque output $\mathrm{Tm}$ given as

$T_{m}=\frac{1}{2} \rho A C_{p}(\lambda, \beta) \frac{V^{3}}{W_{m}}$

The power coefficient is a nonlinear function of the tip speed ratio $\lambda$ and the blade pitch angle $\beta$ (in degrees).If the swept area of the blade and the air density are constant, the value of $C p$ is a function of $\lambda$ and it is maximum at the particular $\lambda$ opt Hence, to fully utilize the wind energy,$\lambda$ should be maintained at $\lambda$ opt , which is determined from the blade design. Then

$P_{\text {Turbine }}=\frac{1}{2} \rho A C_{\text {pmax }} V^{3}$

A generic equation is used to model the power coefficient $C_{P}(\lambda, \beta)$ based on the modeling turbine characteristics described in and. In order to simulate the wind generation system, an empirical expression of $C_{P}(\lambda, \beta)$ has been considered in , such that

$$
\begin{gathered}
C_{p}=[0.5-0.00167(\beta-2)] \sin \frac{\pi(\lambda+0.1)}{12-0.3(\beta-2)} \\
-0.00184(\beta-2)(\lambda-3)
\end{gathered}
$$

In this, the pitch angle $\beta$ is set to zero. The rotational speed is calculated by considering the following equation

$\mathrm{j} \frac{\mathrm{dw}}{\mathrm{dt}}=\mathrm{T}_{\mathrm{m}}-\mathrm{T}_{\mathrm{em}}-\mathrm{F}_{\mathrm{w}}$

Where is Inertia moment of the turbine, axle and generator $F$ Axle friction Tem Electromagnet torque. The characteristic function $C P(\lambda, \beta) \mathrm{Vs} \lambda$ for various values of the pitch angle $\beta \&$ mechanical power Vs rotor speed is 
illustrated in Fig.4.\&5.The maximum value of $\mathrm{Cp}=0.593$ (L. Rodriguez et al 2003) which means that the power extracted from the wind is always less than $59.3 \%$ (Betz 's limit), because of various aerodynamic losses depend on the rotor construction (number and shape of blades, weight, stiffness, etc.). This is the well known low efficiency to produce electricity from the wind. This particular value $\lambda$ opt results in the point of optimal efficiency where the maximum power is captured from wind by the wind turbine. For each wind speed, there exists a specific point in the wind generator power characteristic, MPPT, where the output power is maximized. Thus, the control of the WECS load results in a variable-speed operation of the turbine rotor, so the maximum power is extracted continuously from the wind.

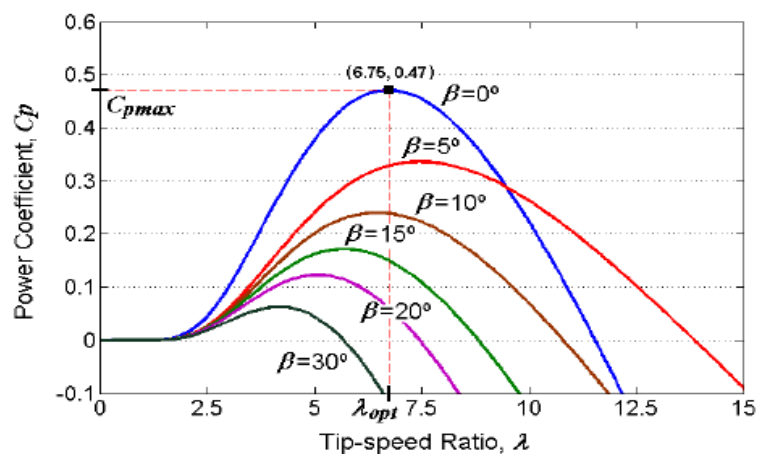

Fig.4. Typical TSR Vs $\lambda$ curve

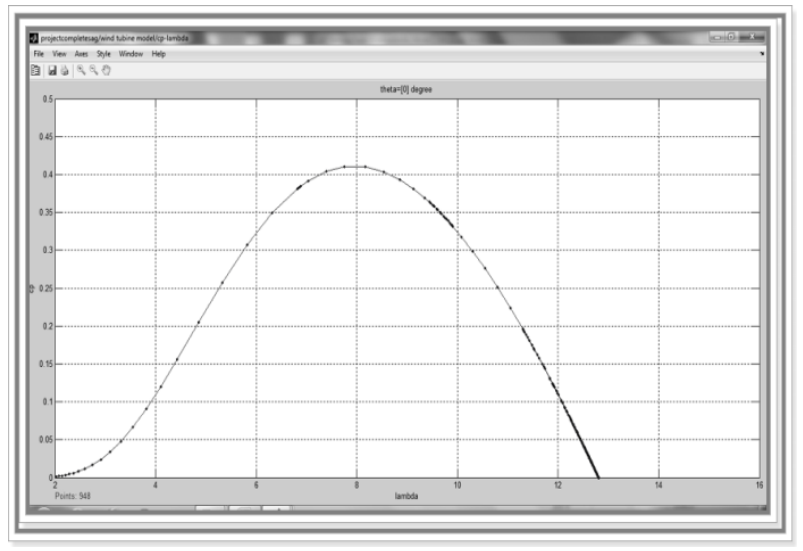

Fig.5. TSR Vs $\lambda$ curve obtained with Simulink

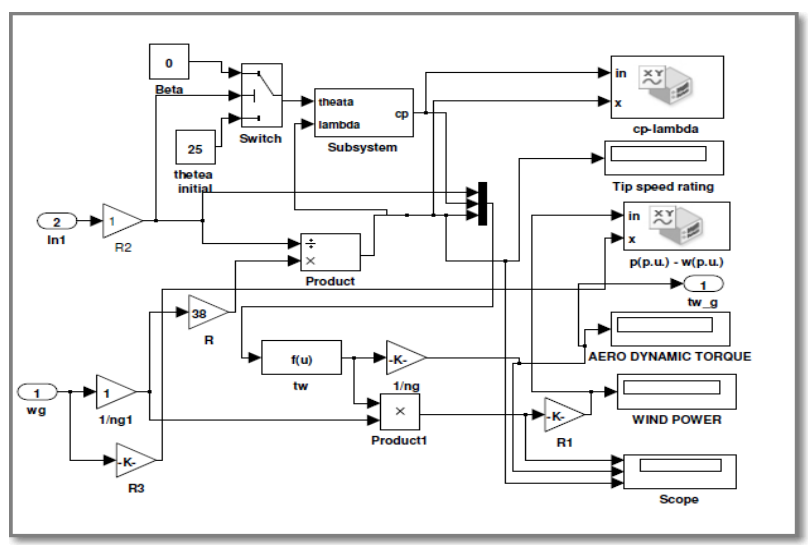

Fig.6 Wind turbine modeling with Simulink
Table 1Wind Turbine parameters

\begin{tabular}{|l|l|l|}
\hline Parameter & Symbol & Value and Units \\
\hline Air density & $\rho$ & $1.205 \mathrm{~kg} / \mathrm{m}^{3}$ \\
\hline Rotor radius & $R$ & $38 \mathrm{~m}$ \\
\hline $\begin{array}{l}\text { Rated wind } \\
\text { speed }\end{array}$ & $\mathrm{V} w$ rated & $11.8 \mathrm{~m} / \mathrm{s}$ \\
\hline Maximum $C p$ & $C p$ max & 0.4412 \\
\hline
\end{tabular}

\subsection{Drive train model}

The drive train of a wind turbine generator system consists of the following elements a blade-pitching mechanism with a spinner, a hub with blades, a rotor shaft and a gearbox with breaker and generator. It must be noted that gearbox is not considered because the analyzed system consists of a wind turbine equipped with a multi-pole PMSG. The common) way to model the drive train is to treat the system as a number of discrete masses connected together by springs defined by damping and stiffness coefficients. In this study, focuses is on the interaction between wind farms and $\mathrm{AC}$ grids , the drive train can be treated as one-lumped mass model for the sake of time efficiency and acceptable precision(M. Yin, et al 2007) (I. Boldea et al 2006)].It is defined by the following equation $\frac{d w}{d t}=\frac{\tau_{e}-\tau_{w-g}}{J_{e q}}-\frac{B_{m}}{J_{e q}} \cdot w_{g}$

where the sub-index $g$ represents the parameters of the generator side, wg is the mechanical angular speed $[\mathrm{rad} / \mathrm{s}]$ of the generator, $\mathrm{Bm}$ is the damping coefficient $[\mathrm{Nm} / \mathrm{s}]$, $\tau$ e is the electromechanical torque $[\mathrm{Nm}], \tau \mathrm{w} \_\mathrm{g}$ is the aerodynamic torque that has been transferred to the generator side (3), which is equal to the torque produced in the rotor side because there is no gearbox, and Jeq is the equivalent rotational inertia of the generator [kg-m2], which is derived from(M. Yin et al 2007)

$J_{e q}=j_{g}+\frac{J_{w}}{n_{g}^{2}}$

where $J g$ and $J_{W}$; are the generator and the rotor rotational inertias $\left[\mathrm{kg}-\mathrm{m}^{2}\right]$ respectively, $n g$ is the gear ratio, which is equal to 1 , because no gearbox is utilized. The model of the one mass drive train implemented in Simulink is depicted in Fig. 7.

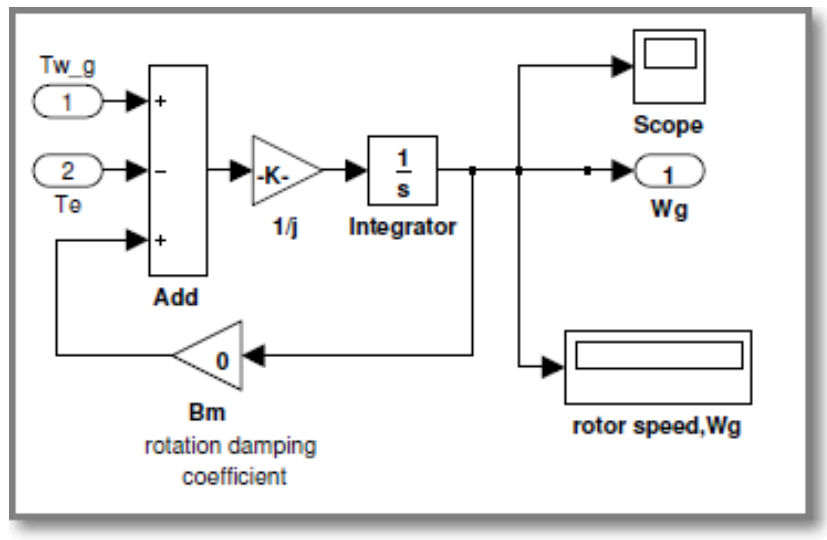

Fig.7 Drive train model with Simulink 
Table 2 Drive train parameters

\begin{tabular}{|l|l|l|}
\hline Parameter & Symbol & Value \\
\hline Gear ratio damping & $\mathrm{ng}$ & 1 \\
\hline $\begin{array}{l}\text { Rotational } \\
\text { coefficient }\end{array}$ & 0 \\
\hline $\begin{array}{l}\text { Equivalent Inertia } \\
\text { (turbine +generator) }\end{array}$ & $\mathrm{Jeq}$ & $0.3 \mathrm{Kg} \cdot \mathrm{m} 2$ \\
\hline
\end{tabular}

\subsection{Pmsg model}

The dynamic model of the PMSG is derived from the two phase synchronous reference frame, which the q-axis is $90^{\circ}$ ahead of the d-axis with respect to the direction of rotation. The synchronization between the $\mathrm{d}-\mathrm{q}$ rotating reference frame and the abc-three phase frame is maintained by utilizing a phase locked loop (PLL) (C. Krause 2002). Fig. 9 shows the d-q reference frame used in a salient-pole synchronous machine (which is the same reference as the one used in a PMSG),

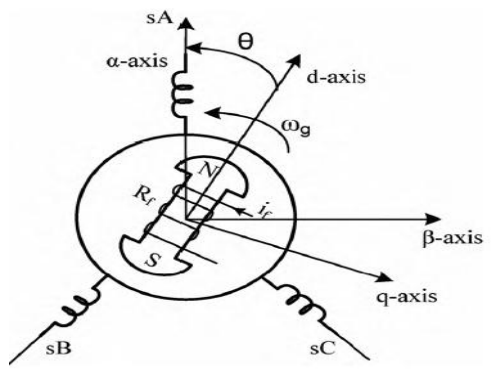

Fig.8 d-q \& $\alpha-\beta$ axis of typical salient pole synchronous Machine.

Where $\theta$ is the mechanical angle, which is the angle between the rotor $\mathrm{d}$-axis and the stator axis. The mathematical model of the PMSG for power system and converter system analysis is usually based on the following assumptions.(L.Rodriguez et al2003),(C.Krause 2002).The stator windings are positioned sinusoidal along the air-gap as far as the mutual effect with the rotor is concerned; the stator slots cause no appreciable variations of the rotor inductances with rotor position; magnetic hysteresis and saturation effects are negligible; the stator winding is symmetrical; damping windings are not considered; the capacitance of all the windings can be neglected and the resistances are constant (this means that power losses are considered constant).The mathematical model of the PMSG in the synchronous reference frame (in the state equation form) is given by(C. Krause 2002), ( I. Boldea 2003).

$\frac{d i_{d}}{d t}=\frac{1}{L_{d s}+L_{q s}}\left(R_{s} i_{d}+w_{e}\left(L_{q s}+L_{i s}\right)+u_{d}\right)$

$\frac{d i_{q}}{d t}=\frac{1}{L_{q s}+L_{i s}}\left(R_{s} i_{q}+w_{e}\left(L_{d s}+L_{i s}\right) i_{d}+u_{q}\right)$

where subscripts $d$ and $q$ refer to the physical quantities that have been transformed into the $d-q$ synchronous rotating reference frame, $R$, is the stator resistance in ohm, $L_{d}$ and $L_{q}$ are the inductances in henry of the generator on the $d$ and $q$ axis, Lid and $L l q$ are the leakage inductances in Henry of the generator on the $d$ and $q$ axis, respectively, is the permanent magnetic flux in $\mathrm{w}$

$\mathrm{Wb}$ and $W e$ is the electrical rotating speed in $\mathrm{rad} / \mathrm{s}$ of the generator, defined by

$w_{e}=p w_{g}$

Where $\mathrm{p}$ is the number of pole pairs of the generator. In order to complete the mathematical model of the PMSG ,the mechanical equation is needed, and it is described by the following electromagnetic torque equation given by (C. Krause 2002)

$\tau_{e}=1.5 p\left(\left(L_{d s}-L_{i s}\right) i_{d} i_{q}+i_{q} \Psi_{f}\right)$

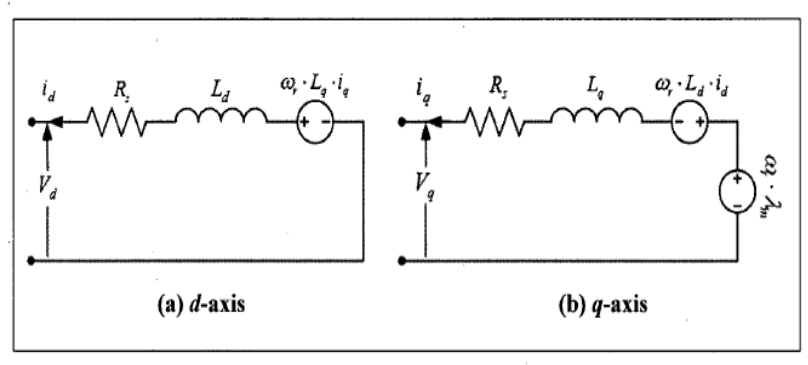

Fig.9 d-q axis equivalent circuit'

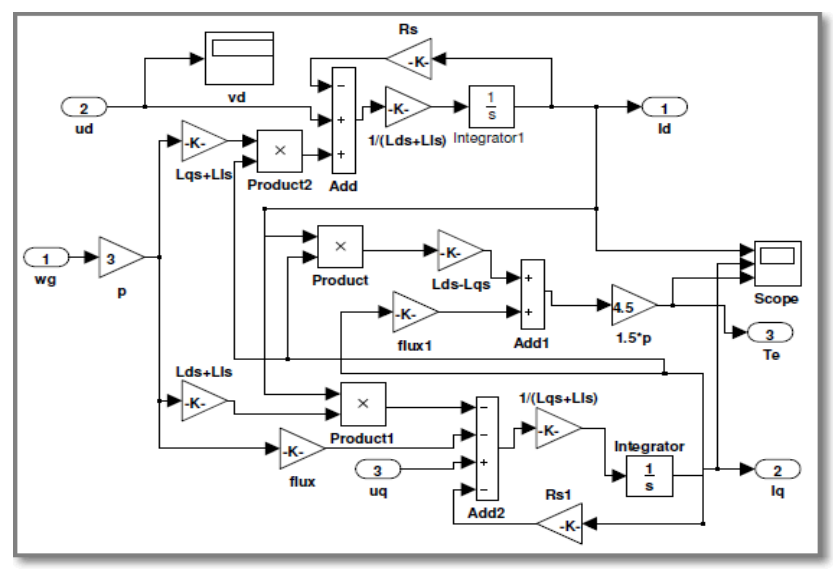

Fig.10 PMSG model with Simulink

Fig. 9. shows the equivalent circuit of the PMSG in de $d-q$ synchronous rotating reference frame The model of the PMSG implemented in Simulink is depicted in Fig. 10.By analyzing the power produced by the wind turbine at various wind and rotor speeds, as depicted in Fig. 12, it can be appreciated that an optimum power coefficient constant Kp opt exists. This coefficient show the generated power associated with the corresponding optimum rotor speed (Z. Lubosny 2003)- (J. G. Slootweg et al 2003), (Z. Lubosny 2003). Kp opt is calculated from individual wind turbine characteristics. By measuring generated power, the corresponding optimum rotor speed can be calculated and set as the reference speed according to(Z. Lubosny 2003)

This coefficient show the generated power associated with he corresponding optimum rotor speed (Z. Lubosny 2003) (J. G. Slootweg et al 2003),( Z. Lubosny 2003). Kp opt is calculated from individual wind turbine 
characteristics. By measuring generated power, the corresponding optimum rotor speed can be calculated and set as the reference speed according to(Z. Lubosny 2003)

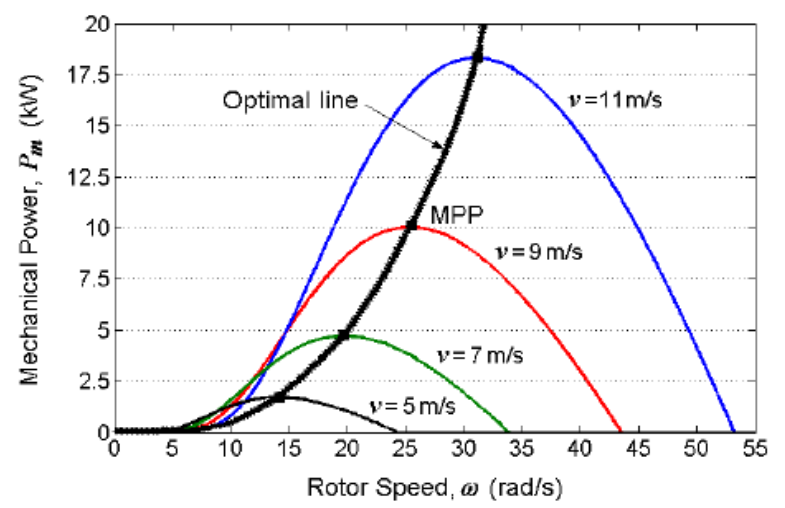

Fig.11 typical Pm-W Curve

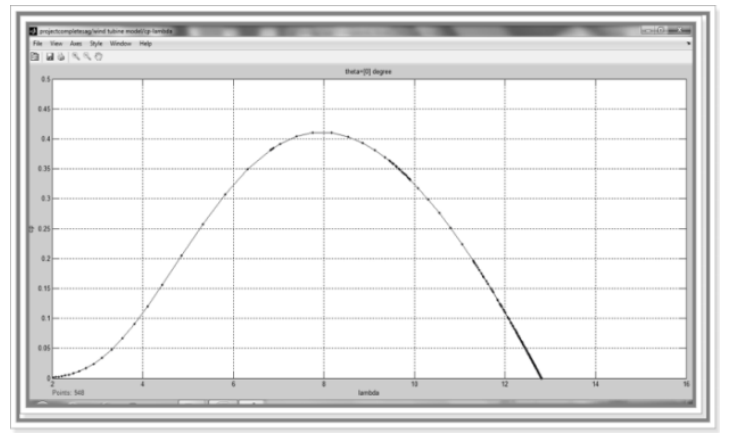

Fig.12 Pm-W obtained with Simulink

$w_{\text {ropt }}=\sqrt[3]{\frac{P_{\text {gen }}}{K_{\text {popt }}}}$

where wr opt is the optimum rotor speed $[\mathrm{rad} / \mathrm{s}]$ and Pgen is the measured generated power [W].This is the base of the well-known Maximum Power Point Tracking (MPPT) (G. Ramtharan et al, 2007), from the prior treatment of the wind turbine model it can be appreciated that in order to extract the maximum amount of power from the incident wind, $\mathrm{Cp}$ should be maintained at a maximum. In order to achieve this objective, it can be appreciated from Fig.11 that the speed of the generator rotor must be optimized according to instantaneous wind speed (this optimization is achieved by using (14)

Table 3 PMSG parameters

\begin{tabular}{|l|l|l|}
\hline Parameter & Symbol & Value \\
\hline Rated generated power & $\mathrm{P}_{\mathrm{g}}$ rated & $2 \mathrm{MW}$ \\
\hline Rated mechanical Speed & $\mathrm{W}_{\mathrm{g}}$ rated & 2.18 \\
\hline Stator resistance & $\mathrm{R}_{\mathrm{s}}$ & $0.08 \Omega$ \\
\hline Stator $d$-axis inductance & $\mathrm{L}_{\mathrm{ds}}$ & $0.334 \mathrm{H}$ \\
\hline Stator $q$ - axis inductance & $\mathrm{L}_{\mathrm{qs}}$ & $0217 \mathrm{H}$ \\
\hline Stator leakage inductance & $\mathrm{L}_{\mathrm{is}}$ & $0.0334 \mathrm{H}$ \\
\hline Permanent magnet flux & $\boldsymbol{\Psi}_{\mathrm{f}}$ & $0.4832 \mathrm{~Wb}$ \\
\hline Pole pairs & $\mathrm{P}$ & 3 \\
\hline
\end{tabular}

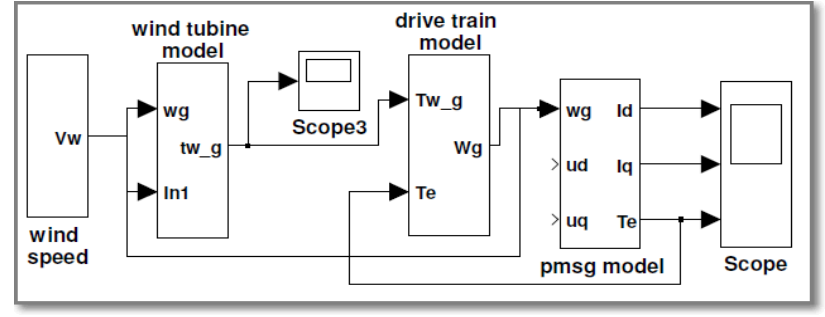

Fig.13 Complete proposed model of WECS with Simulink

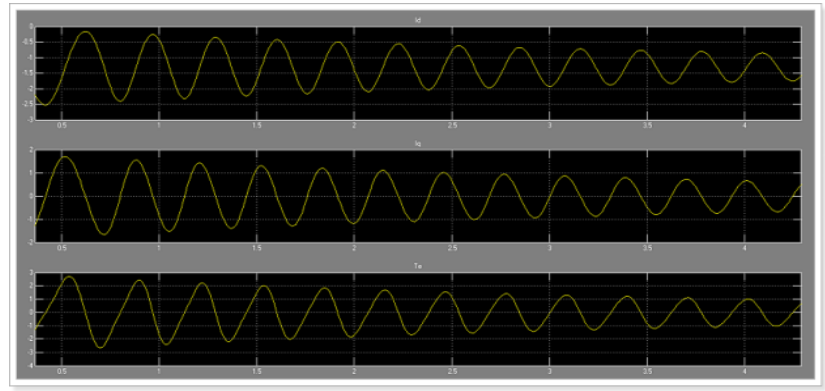

Fig. 14.Graph shows variation of Id,Iq and Torque Vs Time

\section{Conclusions}

The paper presents the complete model of the variable speed wind turbine with PMSG The complete model consists of a PMSG model, wind speed model, wind turbine model and a drive train model. MATLAB/Simulink is implemented to build the dynamic model of the wind turbine with PMSG and simulations have been conducted to validate the model. $C p$ curves and power-speed characteristics have been obtained. The generator has been modelled in the $\mathrm{d}-\mathrm{q}$ synchronous rotating reference frame, taking into account different simplifications. Moreover, the concept of the maximum power point tracking has been presented in terms of the adjustment of the generator rotor speed according to instantaneous wind speed.

\section{References}

Global wind energy council (GWEC) global wind 2012 report available online at http://www.awea.org/publication/reports.

M.Chinchilla, S.Arnaltes, I.C.Burgos, (2006) Control of Permanent Magnet Generators Applied to Variable-Speed Wind-Energy Systems Connected to the Grid. IEEE Transactions on Energy Conversion, vol. 21, no. 1,pp. 130-135.

J.G.Slootweg, S.W.H.deHaan, H.Polinder, W. L. Kling,(2003) General Model for Representing Variable Speed Wind Turbines in Power System Dynamics Simulations, IEEE Transactions on Power Systems, vol. 18,no. 1,pp. 144-151.

Sanjiba kumar Bisoyi , R.K.Jarial , R.A.Gupta, (2013) A review of the state of the art of generators and power electronics converter topologies for wind energy conversion system IJETAE Volume 3, Special Issue 3: ICERTSD, pages 283291.

M.Yin, G.Li, M.Zhou, C.Zhao, (2007), Modelling of the wind turbine with permanent magnet synchronous generator for integration, IEEE Power Engineering Society General Meeting, Tampa, Florida, pp. 1-6.

G.Ramtharan, N.Jenkins, (2007), Modelling and Control of SynchronousGenerators for Wide-Range Variable-speed Wind Turbines, Wind Energy, Wiley Interscience, vol. 10, pp. 231-246.

O.Wasynczuk, D.T.Man, J.P.Sullivan,(1981), Dynamic behavior of a class of wind turbine generators during random wind fluctuations, IEEE Trans. Power App. Syst., vol. 100, pp. 2837-2845.

P.M.Anderson, A.Bose, (1983), Stability simulation of wind turbine systems, IEEE Trans. Power App. Syst., vol. 102, pp. 3791-3795.

T.Ackermann,(2005) Wind Power in Power Systems, John Wiley \& Sons, Ltd, UK. 
P.C.Krause, O.Wasynczuk, S.D.Sudhoff, (2002) Analysis of Electric Machinery and Drive Systems, John Wiley \& Sons Inc, New Jersey.

C.H.Ong, (1998), Dynamic Simulation of Electric Machinery, Prentice Hall, New Jersey.

MATLAB $®$ and Simulink $®,(2010)$ Math Works.

K.Raiambal, C.Chellamuthu, (2002), Modeling and Simulation of Grid Connected wind electric generating system, TENCON '02.Proceedings. IEEE Region 10 Conference on Computers, Communications, Control and Power Engineering,vol.3, pp.1847-1852.

Alejandro Rolan, Alvaro Luna, Gerardo Vazquez, Daniel Aguilar Gustavo Azevedo,(2009), Modeling of a Variable Speed Wind Turbine with a Permanent Magnet Synchronous Generator, IEEE Industrial Electronics, 2009. ISIE 2009. IEEE International Symposium on, pp. $734-739$.

L.Rodriguez, 1.C. Burgos, L. Amalte, (2003) Sistemas E6licos de Produccion de Energia Electrica. Madrid: Editorial Rueda S.L.

I.Boldea, (2006), Synchronous Generators. United States of America: Taylor and Francis.

Z.Lubosny, (2003), Wind Turbine Operation in Electric Power Systems. Berlin:Springer.

\section{Author's biography}

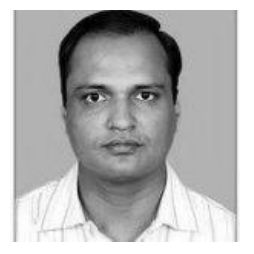

Sanjiba Kumar Bisoyi graduated in 1992 with degree in Electrical Engineering from the Institution of Engineers India, Calcutta. He received his master degree with honors in electrical engineering (Power Electronics) from RGPV Bhopal M.P. in 2004 and is currently pursuing the Ph.D. from NIT Hamirpur (HP) \& working as Asst. Prof. at JSS Academy of Technical Education, Noida. Field of interest: Power Electronics, Electric Drives FACTS Devices, power Quality \& Renewable Energy Sources. He has published more than three papers in reputed national and international conferences.

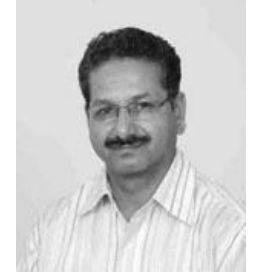

Dr.Rajkumar Jarial received his Bachelor's degree [B.Sc. Engineering (Electrical Engg.) And Master's Degree (Power System) in 1989 \& 1992 respectively from the National Institute Technology (NIT), Kurukshetra, Haryana, India .PhD from Rajasthan University in 2006 Since October 1994, he was an Assistant Professor and became an Associate Professor in 2008 in the department of Electrical Engineering, NIT, Hamirpur, India. His current research interest includes Power Electronics based drives and High Voltage Engineering. Renewable Energy Sources.

Prof. R A Gupta (M'08) received the B.E. degree in electrical engineering and the M.E. degree in control systems from the University of Jodhpur, India, in 1980 and 1984, respectively, and

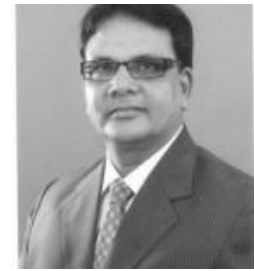
the Ph.D. degree from IIT Roorkee, Roorkee, India (formerly University of Roorkee) in 1996. In 1982, he was an Assistant Professor in the Department of Electrical Engineering, University of Jodhpur, Jodhpur, India. In November 1990, he joined as a Reader and became a Professor in 1999 at the Department of Electrical Engineering, Malviya National Institute of Technology, Jaipur, India. His current research interests include power electronics, electrical machines, and drives. Prof. Gupta is a Fellow of Institute of Engineers, India, and a Life Member of the Indian Society for Technical Education and the Indian Society for Continuing Engineering Education. 